\title{
¿Medios versus redes? Posverdad en la lógica de la multitud
}

\section{Media versus networks? \\ Post-truth in the logic of the crowd}

DOI: https://doi.org/10.29166/tyc.v1i20.2168

\begin{abstract}
Wilson Benavides Vásquez
Licenciado en Comunicación Social por la Universidad Central del Ecuador. Magíster en Ciencias Políticas por la Facultad Latinoamericana de Ciencias Sociales (FLACSO). Fue becario de Unión Latina de UNESCO así como de Flacso-Ecuador. Ha sido periodista político y de investigación en los principales diarios del país; asesor parlamentario en la Asamblea Nacional y analista político y editor de contenidos en varias instituciones del Estado. Su línea de investigación se basa en temas de populismo y cultura política, medios de comunicación y organizaciones partidistas.
\end{abstract}

Correo: wilsonr.benavides@gmail.com

\section{Resumen}

Desde el año 2000, cada lustro se ha producido en Ecuador una revuelta que a veces ha terminado en el derrocamiento del gobierno. Hace 20 años, cayó Mahuad; en 2005, Gutiérrez; en 2010, se produjo una insubordinación contra Correa conocida como el 30S; en 2015, las "banderas negras" rechazaron en las redes y las calles al Ejecutivo y; en 2019, se registró un paro nacional sin precedentes contra el gobierno de Lenín Moreno. Este trabajo compara la caída de Gutiérrez; el 30S y el paro nacional de octubre de 2019 desde la lógica de la multitud, según lo que plantean Hardt \& Negri, e intenta dar respuesta a la siguiente pregunta: ¿En cada una de las revueltas, la llamada posverdad acerca de estos hechos, difundida por lo que conocemos como opinión pública, ha sido redefinida por el poder político o por la acción colectiva de los manifestantes en las calles y en las redes sociales?

Palabras clave: revueltas, redes sociales, acción colectiva, verdad factual.

\begin{abstract}
Since 2000, every five years there has ocurred a rebellion in Ecuador that has sometimes ended in the government overthrow. Twenty years ago, Mahuad goverment fell; in 2005, Gutiérrez; in 2010, there was insubordination against Correa known as the 30-S; in 2015, the "black flags" rejected the Executive in the social networks and in the streets; In 2019, there was an unprecedented national strike against the Lenín Moreno government. This work compares the fall of Gutiérrez; the 30-S and the national strike of October 2019 from the crowd logic, according to the propose of Hardt and Negri, and trying to answer the following question: In each of the revolts, the post-truth call about these events, disseminated by what we know as public opinion, has it been redefined by political power or by the collective action of protesters on the streets and on social media?
\end{abstract}

Keywords: rebellions, social networks, collective action, factual truth. 


\section{Puesta en escena:}

$\mathrm{Al}$ igual que con el aparecimiento de la cultura de masas (Eco, 1984) en el siglo $\mathrm{XX}$, el surgimiento de las redes sociales en el XXI genera un debate con enfoques que van desde la comunicación, hasta la sociología y la cultura política ${ }^{1}$.

En 2009 las protestas por Twitter en Irán (Morozov, 2012) y las elecciones en EE.UU. de 2016 mostraron la incidencia de las redes. Mientras la "primavera árabe" (Gaussens, 2011) no logró consolidarse, la campaña de Trump fue un éxito (Lobo, 2016).

Este texto busca superar el "lugar común" que sostiene que la verdad es monopolio de la opinión pública ${ }^{2}$ (Hardt \& Negri, 2004) y la posverdad surge solo con las redes. Sostengo que la posverdad no necesariamente tiene que ver con éstas, sino que es consustancial a la política (Arendt, 2018).

Entiendo a las redes sociales desde la perspectiva sociológica (Hardt \& Negri, 2014) como una de las expresiones de construcción de lo común característico del paradigma del trabajo inmaterial que hoy organiza la sociedad.

Comparar la caída de Gutiérrez en 2005 , el $30 S$ de 2010 y el paro nacional de 2019 se sustenta en estas consideraciones empíricas: 1) Se producen en diferentes gobiernos con desenlaces distintos. 2)
La opinión pública cambia según cada evento. 3) Los manifestantes producen contenidos propios de las revueltas.

El texto, organizado en cuatro partes: 1. Puesta en escena; 2. Debate conceptual; 3. Análisis de casos; y 4. Conclusiones, busca responder la siguiente interrogante: ¿En cada una de las revueltas, la (pos) verdad (Arendt, 2018) acerca de estos hechos difundida por la opinión pública (Hardt \& Negri, 2004) es (re) definida por el gobierno o por la $a c$ ción colectiva (Tarrow, 2004) de los manifestantes?

\section{Debate conceptual}

\subsection{El trabajo inmaterial y la sociedad en red}

Hardt \& Negri (2004) explican que en la era global hay un desplazamiento del paradigma del trabajo industrial por el del trabajo inmaterial, que define a la sociedad.

La hegemonía del trabajo inmaterial tiende a transformar la organización de la producción pasando de las relaciones lineales de la cadena de montaje a las relaciones innumerables e indeterminadas de las redes distribuidas, donde la información, comunicación y cooperación se convierten en normas de producción y la red pasa a ser la forma de organización dominante. (Hardt \& Negri, 2004: 142-143)

Justamente se acaba de publicar el texto "Cultura política de la democracia en Ecuador y en las Américas, 2018/19: Tomándole el pulso a la democracia”, elaborado por la Facultad Latinoamericana de Ciencias Sociales (Flacso), la Universidad San Francisco, la Universidad de las Américas, y LAPOP, donde se analiza la relación entre las redes sociales y la democracia en la región, entre otros temas.

2 En este trabajo acojo la definición de opinión pública de Hardt y Negri (2004) para referirme a los medios de comunicación convencionales (prensa, radio y TV) generalmente de propiedad privada-corporativa. Los autores sostienen que los medios y las encuestas son los ingredientes esenciales de la opinión pública. 
El trabajo inmaterial se caracteriza por la indefinición entre el tiempo del trabajo y del ocio y por relaciones laborales flexibles, móviles y precarias; crea conocimiento e información; funciona en red y puede ser intelectual (produce ideas, símbolos, códigos, textos, imágenes) o afectivo (crea relaciones y afectos) (Hardt \& Negri, 2004)

La forma de red, característica de la producción inmaterial, aparece en todas las facetas de la vida social como la manera de entender todo, desde las funciones neuronales a las organizaciones terroristas. Esta es la función de una forma hegemónica de producción: transformar la sociedad a su imagen y semejanza (Hardt \& Negri, 2004: 145)

\subsection{La construcción de lo común}

Si el trabajo inmaterial define el contexto global, es necesario, dicen los autores, superar los conceptos de clase obrera, masas y pueblo, porque reducen a una "identidad única" la multiplicidad de posiciones existentes en la red.
Hardt \& Negri (2004) apuestan por la multitud ${ }^{3}$, que surge de la "subjetividad producida en la interacción entre singularidad y comunalidad"4. En la multitud, "las singularidades que la integran, interactúan y se comunican sobre lo común", que se va construyendo y se expresa a través de "lenguajes que interaccionan y se mezclan para formar un poder de comunicación y cooperación" 5 (Ibid: 233-234), haciendo del lenguaje un "poderoso lugar de conflicto y resistencia" (Hardt \& Negri 2004: 169-170).

Pobres y emigrantes son sujetos de la multitud, "inclusiones diferenciales, singularidades activas, cooperando en esta construcción de lo común" (Hardt \& Negri: 166-167). Al dejar de ser identidades convirtiéndose en singularidades, "incluyen a otros sujetos activos de la producción biopolítica"; y mediante su movilidad y comunalidad amenazan al sistema global ${ }^{6}$ (Hardt \& Negri, 2004: 169-170).

Esta construcción de lo común se concreta en hábitos que "se forman en comunicación y colaboración con otros", pero en el contexto global, son reemplazados por performances, la "noción nu-

3 Hardt y Negri sostienen que este concepto proporciona "un modelo en el que nuestras expresiones de singularidad no quedan reducidas ni disminuidas en nuestra comunicación y colaboración con otros en la lucha” (Ibid: 255) La multitud para ellos está supeditada a la existencia de un proyecto político donde los pobres y los emigrantes serán sus protagonistas debido a su inherente riqueza cultural, comunicativa y colaborativa.

4 El término "comunidad" se aplica con frecuencia para aludir a una unidad moral colocada por encima de la población y sus interacciones a modo de poder soberano. Lo común, en cambio, no es sinónimo de una definición tradicional de comunidad o de lo público, sino que se basa en la comunicación entre singularidades y emerge gracias a los procesos sociales y colaborativos de la producción. El individuo se disuelve en el marco unitario de la comunidad. En cambio, en lo común, las singularidades no sufren merma alguna, sino que se expresan libremente a sí mismas. (Hardt \& Negri, 2004: 241)

5 En la concepción polifónica del relato ya no hay un centro que dicte el sentido de los acontecimientos. Este surge del intercambio entre todas las singularidades en diálogo (...) La narración polifónica plantea en términos lingüísticos una noción de la producción de lo común en una estructura de red abierta y distribuida (...) En la organización política como en los relatos, se produce un diálogo constante entre diversos sujetos singulares, una composición polifónica de los sujetos y un enriquecimiento general de cada uno a través de esta constitución común (...) que produce nuevas subjetividades y nuevos lenguajes. (Hardt \& Negri, 2004: 248)

6 Las luchas de estos grupos, aseguran Hardt \& Negri (2004) son “(..) afirmaciones de poder biopolítico (...) Durante el siglo XX (...), los movimientos de la gente pobre han superado la fragmentación, el desánimo, la resignación e incluso el pánico que puede crear la pobreza, para plantear sus agravios a las autoridades nacionales y exigir una redistribución de la riqueza” (Ibid: 167) 
clear de producción de lo común"7 (Ibid: 234-235).

Cada forma de trabajo que produce un bien inmaterial, como una relación o un afecto, la solución de problemas o la información, desde el trabajo del representante comercial hasta los servicios financieros, son un performance donde el propio acto es el producto (Hardt \& Negri, 2004: 237)

\subsubsection{La multitud en movimiento}

El proyecto de la multitud se concreta en la movilización de lo común expresado en la revuelta; que, en el plano intensivo, ahonda la lucha local y; en el extensivo, articula nuevas luchas en otros lugares.

En el plano intensivo, el antagonismo compartido de cada lucha local se forma en el diálogo con tradiciones y hábitos locales y esa riqueza común de explotados y expropiados se traduce en conductas, hábitos y performatividad. En una revuelta, lo que llama la atención son las formas comunes de vestir y gesticular, los modos de relación y comunicación (que son) síntomas de sueños, deseos y maneras de vivir comunes: el potencial común que el movimiento ha puesto en marcha (Hardt \& Negri, 2004: 250)

En el plano extensivo, las revueltas se propagan geográficamente en un "ciclo internacional de luchas, pasando de un contexto local a otro por comunicación de prácticas y deseos comunes"8 (Ibid: 251)

En cada ciclo de lucha, lo común que se moviliza extensivamente no es solo la existencia de un enemigo común (...) sino también los métodos comunes de vida y el anhelo de alcanzar un mundo mejor. El ciclo global de luchas adopta la forma de una red distribuida, donde cada lucha local funciona como un nodo que comunica con todos los demás sin que exista un centro (... ). Cada lucha sigue siendo singular vinculada a sus condiciones locales, pero está inmersa en una red común que organiza la multitud y la moviliza. (Hardt \& Negri, 2004: 251 y 254)

\subsection{La opinión pública como campo de disputa}

La opinión pública ha sido objeto de reflexión, pero en la era global adquiere centralidad. Hardt \& Negri (2004) exploran la emergencia de una opinión

7 Paolo Virno, en Hardt \& Negri (2004) compara el trabajo inmaterial con el performance de la producción lingüística. Este autor, asegura que, en primer lugar, "el lenguaje siempre se produce en común y jamás es producto de un solo individuo, sino que lo crea una comunidad lingüística en comunicación y colaboración". En segundo lugar, dice, "la performance lingüística requiere la capacidad para innovar en un medio cambiante, sobre la base de las prácticas y los hábitos del pasado (...)”. La facultad del lenguaje, es decir, la capacidad genérica del habla (...) es más que un componente del trabajo inmaterial” y según Virno, "constituye una de las claves para entender todas las formas que éste adopta" (Ibid: 238)

8 Hardt y Negri (2004) recuerdan que hacia finales del siglo XX, los movimientos de protesta y las revueltas eran analizados desde dos modelos principales; por un lado, "el que se basaba en la identidad de la lucha y su unidad se organizaba bajo un liderazgo central" Por otro lado, el que sostenía que "cada grupo debía expresar su diferencia y conducir su lucha de manera autónoma" (Ibid: 255) Estos dos modelos dominantes, aseguran los autores, "planteaban una elección clara: o lucha unitaria supeditada a la identidad central, o luchas diversas que afirmen nuestras diferencias" (Ibid: 255), pero ahora: El nuevo modelo en red desplaza a ambos modelos ya que (...) muchos grupos a los que se tenía anteriormente como antagonistas, actuaron juntos sin necesidad de una estructura central y unificadora que subordinase o declarase temporalmente suspendidas sus diferencias. La multitud sustituye el par contradictorio identidad/diferencia por el par complementario singularidad/comunalidad (Hardt \& Negri, 2004: 255) 
pública global $^{9}$, donde medios y encuestadoras son sus factores esenciales.

La opinión pública (...) es un campo de conflicto donde se expresan las relaciones de poder en las que se interviene políticamente por medio de la comunicación, la producción cultural y las formas de producción biopolítica. Es un terreno asimétrico, puesto que los medios están controlados por grandes corporaciones (...) (Ibid: 303)

A medida que las corporaciones mediáticas van fundiéndose en grandes conglomerados, "se homogeniza la información que distribuyen" haciendo -a veces- que "los medios funcionen como portavoces gubernamentales (...)" (Hardt \& Negri, 2004:301-302)

\subsection{La verdad factual como posverdad}

Luego de un debate sobre la verdad, Arendt (2018) hace alusión al mito de la caverna ${ }^{10}$ y se pregunta si una sociedad puede vivir sin libertad, sin justicia, sin paz o sin verdad.

Explica que existen diferentes "verdades": científica, racional, filosófica y factual, definida como:

La verdad (que) está relacionada con otros, referida a acontecimientos y circunstancias en las que muchos están implicados; se establece al ser presenciada y depende de los testimonios; existe solo si se habla de ella y es política (Arendt, 2018: 34-35)
Los hechos, asegura, "precisan de un testimonio y de testigos fiables que los confirmen", por lo que hay una "tendencia a transformarlos en opiniones, desdibujando la frontera entre ambos" (Arendt, 2018: 33)

Los hechos dan forma a las opiniones y éstas, "inspiradas por pasiones e intereses diversos" pueden divergir ampliamente, pero ser legítimas si respetan la verdad factual.

Si no se aceptan los juicios objetivos del narrador de la verdad factual -presenciada y vista con los ojos y no con la mentesurge la sospecha que el negarla o tergiversarla, es natural al campo político (Arendt, 2017: 90)

Aunque la verdad factual nunca contradice a la razón porque "las cosas podrían haber ocurrido según sostiene el observador" (Ibid: 90), su fragilidad provoca que:

Las mentiras resultan más verosímiles para la razón que la realidad misma, porque quien miente tiene la ventaja de conocer lo que su audiencia desea escuchar (y) ha preparado su relato esmerándose en que resulte creíble, mientras que la realidad tiene la costumbre de enfrentarnos con lo inesperado (Arendt, 2018: 90)

La negación deliberada de la verdad factual -habilidad para mentir- y la capacidad de cambiar los hechos -capacidad de

9 Definida por los autores como "una nueva superpotencia que se extiende más allá de las instituciones políticas de representación, y su aparición es un síntoma de la crisis general de representación democrática de la sociedad global". Actúa mediante la "expansión de una visión utópica que sostiene que los medios presentan informaciones objetivas que permiten a los ciudadanos formarse sus propias opiniones, las que, a su vez, les son ratificadas fielmente por las encuestas de opinión de dichos medios" (Hardt y Negri, 2004: 301 y 303)

910 Recuperado de: http://www.unsam.edu.ar/escuelas/ciencia/docs/Platon\%20El\%20mito\%20de\%20la\%20caverna\%20\%2oAdmis-i\%C3\%B3n\%2oIEU.pdf 
actuar- se hallan interconectadas, afirma Arendt (2018), ya que "deben su existencia a la misma fuente: la imaginación y se desarrollan en el mismo campo: la política”, donde el arte de la mentira, se sustenta en los "profesionales de las relaciones públicas y de resolución de problemas ${ }^{11}$ (Ibid: 93-96)

\subsection{Los repertorios de movilización}

Tarrow (2004) explica que uno de los modelos clásicos de la acción colectiva $^{12}$ son las huelgas y manifestaciones. La huelga es expresión de la clase obrera y actúa dentro de canales normados jurídicamente. Las manifestaciones, en cambio, pueden extenderse de un lugar a otro y combinar muchos actores y temas ${ }^{13}$. En la era global (Hardt \& Negri, 2004), asistimos al declive de los movimientos sindicales $\mathrm{y}$ al surgimiento de nuevos repertorios de movilización: innovación en los márgenes, cambio paradigmático y movimientos multiformes. ${ }^{14}$ (Tarrow, 2004: 147, 148-151)

\section{Análisis de casos}

\subsection{La caída de Gutiérrez}

La caída de Gutiérrez (2005) representa un punto de inflexión en el ciclo de inestabilidad que vivió Ecuador desde finales de los 90 hasta mediados de los $2000^{15}$.

La diferencia con las revueltas que derrocaron a Bucaram (1997) y Mahuad (2000) es que no fue consecuencia de una crisis, sino una expresión de indignación moral contra la clase política, plasmada en la consigna "fuera todos" (Hurtado, $2005)^{16}$.

11 Para los relacionistas públicos, "la mitad de la política es la creación de imágenes y la otra mitad, el arte de hacer creer a la gente en dichas imágenes”, mientras que para los profesionales de la resolución de problemas -que han llegado al gobierno desde las universidades, los laboratorios de ideas, etc.- a pesar de su puesto, de su educación y de su obra, "creyeron que la política era una variante de las relaciones públicas aceptando las premisas psicológicas subyacentes a esta creencia” Estos últimos, dice Arendt, ansiaban encontrar fórmulas, preferiblemente expresadas en lenguaje pseudo matemático que unificaran los fenómenos más dispares con los que les enfrentaba la realidad; es decir, ansiaban (...) explicar y predecir los hechos políticos e históricos como si fueran necesarios y fiables como los físicos creyeron que eran los fenómenos naturales. A diferencia del científico de la naturaleza, el historiador y el político, abordan los asuntos humanos que deben su existencia a la capacidad del hombre para la acción (...). Si tienen apetito de acción y están a la vez enamorados de las teorías apenas tendrán la paciencia del científico de la naturaleza para esperar a que las teorías y explicaciones hipotéticas sean verificadas o negadas por los hechos. En lugar de esto, experimentarán la tentación de hacer que su realidad encaje en la teoría, y así se desprenderán de la contingencia de la realidad, la cual ha sido creada por el hombre y por consiguiente, podría haber sido de otra manera. (Arendt, 2018: 93-96)

12 Según Tarrow (2004) la acción colectiva puede ser breve o mantenida, institucionalizada o subversiva, monótona o dramática. Y en su mayor parte se produce en el marco de las instituciones por parte de grupos constituidos con objetivos específicos (Tarrow, 2004: 24)

13 Como apoyo a una reivindicación, contra un oponente, para expresar la existencia de un grupo o su solidaridad con otro, para celebrar una victoria (...) Las manifestaciones se convirtieron en la forma modular clásica de la acción colectiva. De un desplazamiento incontrolado de descontentos de un lado para otro, la manifestación de protesta ha terminado convirtiéndose en la principal expresión no electoral de la política civil moderna (Tarrow, 2004: 147)

14La innovación en los márgenes a corto plazo puede limitarse a animar una forma convencional de acción colectiva añadiéndole elementos lúdicos y carnavalescos o feroces y amenazantes, pero con el tiempo pueden transformarse en formas nuevas. El cambio paradigmático se produce en los picos de los ciclos de protesta en los que surgen nuevos actores y nuevos marcos de significados y sobre la marcha se inventan nuevas formas de acción colectiva. Los movimientos multiformes tienen acceso a una variedad de formas de acción colectiva ya sea por sí solos o en combinación. Esta flexibilidad les permite combinar las exigencias con la participación de amplias coaliciones de actores, en las mismas campañas de acción colectiva y centrarse tanto en el interior del proceso político como en el exterior. (Tarrow, 2004: 148-151)

15 Entre 1997 y 2007, Ecuador tuvo siete presidentes; hubo un feriado bancario, se dolarizó la economía, y se aprobó una constitución (1998)

16 Recuperado de: https://www.eluniverso.com/2006/04/20/ooo1/8/1AEE624927BE44A5A9343F6F294041ED.html 
Los forajidos (apelativo con el que Gutiérrez calificó a los manifestantes) no eran parte de una organización sindical o indígena, sino que integraban una multitud (Hardt \& Negri, 2004) conformada por sectores académicos, colectivos urbanos, estudiantiles y ciudadanos, que buscó sanear todo el sistema.

Este objetivo común se canalizó mediante el uso alternativo de un medio tradicional como radio La Luna ${ }^{17}$ que abrió sus micrófonos y cada ciudadano, cada singularidad activa, fue construyendo lo común (Hardt \& Negri, 2004) invisibilizado -en un primer momentopor la opinión pública ${ }^{18}$.

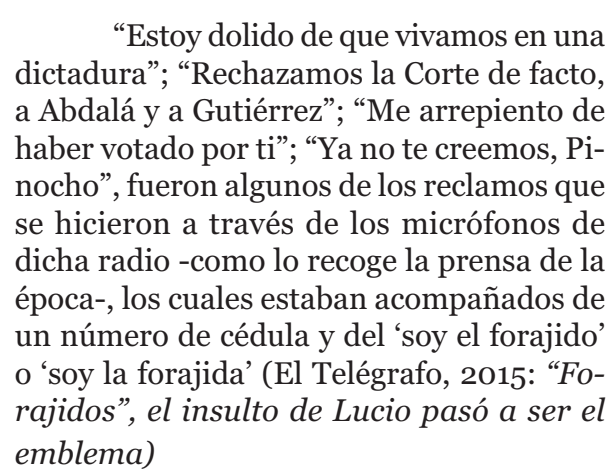

El hecho que los ciudadanos dieran su nombre y número de cédula permitió neutralizar la respuesta del gobierno de minimizar el descontento homogenizando la audiencia (Hardt \& Negri, 2004).

Una señora llamó por teléfono a las 19 hoo del 13 de abril de 2005. Se decía indignada porque el ministro de Gobierno del gutierrato se había burlado de las marchas de ese día: "dijo que había gente que prefería trabajar” (...) Dicha señora negó que no quisieran trabajar, sino que después de sus labores y de servir la merienda a su familia, salía a protestar. (El Telégrafo (2015) "Forajidos”, el insulto de Lucio pasó a ser el emblema)

Si en la era global, la opinión pública reemplaza a la representación democrática (Hardt \& Negri, 2004), en 2005 ambas fueron interpeladas desde una innovación en los márgenes (Tarrow, 2004) expresada en una radio.

\subsection{S: la posverdad en acción}

Esta revuelta se produjo en un contexto de confrontación entre el gobierno de Correa y la opinión pública prácticamente desde el inicio de su mandato (2007), acentuada con la aprobación de la nueva Constitución (2008) ${ }^{19}$

El gobierno concebía a los medios como "aparatos ideológicos" de las clases dominantes (Altusser, 2005) a los que respondió con un aparato de propaganda que definía la agenda y contrarrestaba la información "errónea y mal intencionada" de los medios, definidos como "actores políticos sin legitimidad democrática”.

Esta visión se acentuó durante el 3oS, cuando el gobierno los acusó de participar como "partido medial de derecha" (Quintero y Sylva, 2010: 68) al conocer de antemano una supuesta conspiración para dar un golpe de Estado.

17 El Telégrafo. Recuperado de: https://www.eltelegrafo.com.ec/noticias/politica/3/forajidos-el-insulto-de-lucio-paso-a-ser-el-emblema 18 El Universo. Recuperado de: https://www.eluniverso.com/2005/o5/o9/ooo1/1065/48AF361B53C440849B24EBF1D41585E9.html

19 Que estableció expedir una Ley de Comunicación, así como la separación de la banca de la propiedad mayoritaria de los medios, que se concretaría tres años después en la consulta popular del 2011. 
Los medios han reemplazado a los partidos como vehículos de representación de intereses de los grandes grupos económicos (Quintero y Sylva, 2010: 80) (Ibid: 68)

Esta revuelta se definió en el lenguaje como campo de conflicto y resistencia (Hardt \& Negri, 2004). Mientras para la opinión pública, el $30 \mathrm{OS}$ fue un "motín policial" provocado por la "imprudencia" de Correa, para el gobierno se trató de un "intento de golpe de Estado, secuestro y magnicidio". Estas dos tesis entraron en disputa.

El 30S no se perderá en la memoria porque siempre estaremos sedientos de verdad, y la verdad, en estos casos tiende a ser escamoteada por los interesados en ocultar sus siniestros propósitos (...). (Correa, 2011)

El 3oS desplegó las operaciones de la verdad factual (Arendt, 2018). Por un lado, la negación deliberada de los hechos que hicieron los medios ${ }^{20}$; y por otro, la capacidad del gobierno de cambiar$\operatorname{los}^{21}$ a través de varios argumentos ${ }^{22}$ :

Ahora resulta que no hay hechos sino versiones de los mismos (...) Ese discurso (de la opinión pública) se sustenta en tres ideas: 1 . No hubo intento de golpe de Estado sino una rebelión provocada por la "prepotencia" del Presidente; 2. No hubo secuestro: el Presidente estuvo voluntariamente en el hospital de la Policía y podía salir en cualquier momento, y 3. No hubo intento de magnicidio: es una invención, un show mediático inventado por el gobierno. (Quintero y Sylva, 2010: 83)

En el 30S, el narrador de la verdad factual (Arendt, 2018) no fue la opinión pública ni las singularidades que construyen lo común (Hardt \& Negri, 2004) como en 2005, sino la versión del gobierno que decantó incluso en acciones judiciales contra el diario El Universo por un artículo que la desmentía ${ }^{24}$.

Lo que ocurre en realidad es que el Dictador (Rafael Correa) por fin comprendió que no tiene cómo demostrar el supuesto crimen del $30 \mathrm{~S}$, ya que todo fue producto de un guion improvisado, para ocultar su irresponsabilidad de irse a meter en un cuartel sublevado, abrirse la camisa y gritar que lo maten, como todo un luchador de cachascán que se esfuerza en su show en una carpa de circo de un pueblito olvidado. (El Universo, 2011: No a las mentiras)

Desde su capacidad de cambiar los hechos (Arendt, 2018), el oficialismo respondió en dos arenas. Desde la comunicación, con los enlaces sabatinos, la publicación de un libro y un documental ${ }^{25}$. En lo político, integrando una comisión de

20 El Universo. Recuperado de: https://www.eluniverso.com/2011/o3/10/1/1380/muchedumbre-3os-version-oficial-ratificada-aumentada.html

21 El gobierno decretó un estado de excepción bloqueando a la opinión pública y estableciendo la obligatoriedad de todos los medios de enlazarse a una sola señal, la de la televisión gubernamental.

22 Estos argumentos enfatizan también que el $30 \mathrm{~S}$ se enmarca en una conspiración regional promovida por los EE.UU. contra los gobiernos "progresistas" de América Latina. Citan los fallidos golpes contra Hugo Chávez (2000) y Evo Morales (2008), así como el promovido contra Manuel Zelaya (2009) que sí se concretó. Explican que el $30 S$ es el resultado de una "coyuntura conspirativa” (Quintero y Sylva, 2010) gestada un año antes.

23 La irrupción de un grupo de manifestantes en las instalaciones de Ecuador TV fue justificada totalmente por la opinión pública. Recuperado de https://www.eluniverso.com/2010/o9/30/1/1447/manifestantes-reclamaron-espacio-television-publica.html

24 El director de Opinión de Diario El Universo, Emilio Palacio, escribió el artículo "No a las mentiras". Recuperado de: https://www.eluniverso.com/2011/02/06/1/1363/mentiras.html

25 “3oS.La Contrarrevolución” publicado por el Ministerio Coordinador de la Política y el documental "Muchedumbre” del periodista Rodolfo Muñoz, funcionario de medios públicos para la época 
investigación parajudicial ${ }^{26}$. Posteriormente, el $30 \mathrm{~S}$ fue enaltecido por los profesionales del arte de la mentira (Arendt, 2018) al servicio de ese gobierno ${ }^{27}$.

\subsection{Paro nacional de octubre de 2019 y activa- ción digital}

El Decreto 883 de octubre 2019 eliminó los subsidios a los combustibles activando una protesta nacional, que inició con un paro del transporte público que se desactivó a los pocos días, pero luego fue reemplazado por un levantamiento indígena protagonizado por la CONAIE a través de un nuevo repertorio (Tarrow, 2004).
La respuesta oficial fue la represión que dejó, según la Defensoría del Pueblo, 11 fallecidos, más de 1000 heridos y detenidos $^{29}$.

La opinión pública (Hardt \& Negri, 2004) actuó diferente al 2010 y al 2005, convirtiendo la protesta en vandalismo y ocultando, minimizando o justificando la represión. Los medios funcionaron como "portavoces gubernamentales" (Hardt \& Negri, 2004: 301-302)

Esto provocó una indignación ciudadana que descartó convocarse por radio Pichincha optando por plataformas digitales, grupos de Whatsapp, Facebook y Twitter, acusadas por el gobierno de difundir fake news ${ }^{32}$.

26 Integrada por Oscar Bonilla, Carlos Baca y Diego Guzmán, los tres militantes confesos del correísmo, desarrollaron en ese documento la tesis de que el $30 S$ se trató de un "golpe blando" promovido por el ex Presidente Lucio Gutiérrez que utilizó el malestar policial contra el gobierno debido a tres factores 1) La creación de la Comisión de la Verdad que investigó violaciones a los DDHH entre 1984 y 1988. 2) El desmantelamiento de los aparatos de inteligencia policial ligados a la CIA y la eliminación de los tribunales especiales. 3) El retiro de las competencias sobre la expedición de matrículas y licencias de conducir que era exclusivo de la Policía Nacional. El detonante de la revuelta del $30 S$ fue la aprobación de la Ley del Servicio Público (Losep) que homologaba a los policías y militares con el resto de servidores del Estado, suprimiendo o modificando bonificaciones y condecoraciones, entre otros. Hasta 2014, esos procesos dejaron 109 sentenciados, en su mayoría policías. Recuperado de: https://www.elcomercio.com/actualidad/investigacion-30s-109sentenciados.html

27 Cada 30 de septiembre al menos hasta el 2015 se realizaron eventos masivos o conmemorativos con este motivo.

28 El "cambio de paradigma" aparece en los picos de los ciclos de protesta, a través de nuevos actores y nuevos marcos de significados, que sobre la marcha, inventan nuevas formas de acción colectiva (Tarrow, 2004: 148-151). La Confederación de Nacionalidades Indígenas del Ecuador (Conaie) cerró carreteras en las provincias de la sierra centro y norte; se tomó gobernaciones y promovió una masiva movilización hacia Quito.

29 Tanto la Defensoría del Pueblo como la Comisión Multipartidista para investigar el Paro Nacional creada en la Asamblea han ratificado este dato, que sin embargo, no coincide con el proporcionado por otras instituciones oficiales. El Ministerio de Gobierno reconoce 9 fallecidos (solo 3 por muerte violenta); la Fiscalía General 8 y el Ministerio de Salud, 7. Actualmente, otra Comisión Especial promovida por la Defensoría del Pueblo está terminando otro informe sobre el mismo tema.

30 Este hecho provocó que la dirigencia indígena retenga a periodistas y policías en la Casa de la Cultura de Quito, exigiendo "transmitir en vivo" ese evento, y días después esa exigencia fue la misma para entablar el diálogo con el Ejecutivo el 13 de octubre de 2019 luego del cual se derogó el Decreto 883 poniendo fin a la revuelta.

31 Es la radio de la Prefectura de Pichincha que durante las protestas fue clausurada por el gobierno. A diferencia de lo que ocurrió con radio La Luna en 2005, donde varios medios incluso se enlazaron a su señal; en 2019, ningún medio se adhirió a esa emisora.

32 En términos generales, Lobo (2016) define a las noticias falsas como un "rumor producido técnicamente y difundido de forma masiva". Según la ministra Romo, el primer día de protestas, el gobierno identificó 20 noticias falsas, pero el 12 de octubre, ascendieron a 3600. El régimen señaló que las IP de origen de estas noticias en casos esporádicos fue Rusia, Irán y España, pero la mayor parte se produjeron en Venezuela. Para contrarrestar esta información, el gobierno emitió 20 mil mensajes. Recuperado de: https://www.elcomercio.com/actualidad/romo-informe-comision-asamblea-protestas.html Para obtener datos cuantitativos más detallados, se recomienda revisar: www.ecuadorchequea.com. 
Este cambio de paradigma (Tarrow, 2004) configuró una red distribuida que se expresó en las calles y en las redes, donde "la información y las imágenes fueron omnipresentes y sobreabundantes, pero sus fuentes escazas" (Hardt \& Negri, 2004: 301). La opinión pública minimizó la represión, pero las plataformas digitales la denunciaron ${ }^{33}$.

\section{Conclusiones}

4.1 Comprender las redes sociales desde la perspectiva sociológica busca desmitificar su influencia (Morozov, 2011) pasando del análisis de las plataformas digitales al de los procesos que están detrás, en un contexto donde su alcance es todavía incipiente ${ }^{34}$. Según un reciente estudio, apenas 2\% de usuarios habla de política en Twitter, 22,3\% en Facebook y $16,5 \%$ en WhatsApp ${ }^{35}$.

4.2 La posverdad es un concepto anterior a las redes sociales, que surgió a la luz del manejo informativo en Vietnam, donde Arendt (2018) la definió como verdad factual, que al parecer no es monopolio de los medios ni de las redes sino del poder político.
4.3 Durante las revueltas, la opinión pública "se aproxima a las víctimas llamándolas por sus nombres y a los victimarios los denomina en plural como una masa indiferenciada" ${ }^{6}$ (Hurtado, 2005: 72). Sin embargo, en 2019 las víctimas no fueron los manifestantes fallecidos, sino los policías heridos violentamente por aquéllos ${ }^{37}$.

4.4. Según la tabla elaborada, en 2005 y 2019, la incidencia de los medios fue alta, pero con sentidos distintos. En 2005 dieron amplia cobertura a los opositores a Gutiérrez y posteriormente a los forajidos $^{38}$. En 2019, los medios fueron portavoces del gobierno enfatizando el vandalismo de la protesta y reiterando el respeto al status quo. La censura fue a las plataformas digitales ${ }^{39}$. El 30S, en cambio impuso una alta censura a los medios silenciándolos. Las redes alcanzaron incidencia media, pero en apoyo de la versión oficial.

4.5 Durante las revueltas de octubre de 2019 la posverdad fue cuestionada por la acción colectiva de los manifestantes. En 2005 con el uso alternativo de un medio tradicional (La Luna). En 2019, con la ebullición de las plataformas digitales. Por el contrario, en 2010, la versión oficial se impuso sobre los medios y la $a c$ ción colectiva, sacrificando su significado.

33 De forma similar al 3oS, el gobierno de Moreno también denunció un supuesto intento de golpe de Estado en su contra orquestado, esta vez, por autoridades y militantes del movimiento Revolución Ciudadana del ex presidente Correa. La prefecta de Pichincha, Paola Pavón, el ex asambleísta Virgilio Hernández y el activista político Christian González, fueron detenidos acusados del delito de rebelión, posteriormente modificado al de instigación. Los asambleístas Gabriela Rivadeneira, Soledad Buendía, Carlos Viteri y Luis Molina (alterno) pidieron asilo en la embajada de México en Quito y actualmente ya se encuentran en ese país. Los detenidos fueron liberados con medidas sustitutivas a la prisión preventiva como usar grillete electrónico y presentarse periódicamente ante un juez. Ningún dirigente de la CONAIE ha sido detenido, pero se han abierto investigaciones en su contra.

34 De acuerdo con la Encuesta de Condiciones de Vida (ECV)-2014 del INEC, 41,4\% de ecuatorianos mayores de 12 años tenía una cuenta en redes sociales. De este porcentaje, 97,9\% en Facebook; 33,1\% en WhatsApp y 20,4\% en Twitter.

35 Cultura Política de la Democracia en Ecuador y las Américas 2018/19 publicado en 2020. Para este dato, se basó en una encuesta del Barómetro de las Américas LAPOP 2019, realizada a 1.533 ciudadanos mayores de 16 años.

36 En 2005 la figura de Julio García, fotógrafo chileno fallecido por asfixia durante las protestas contra Gutiérrez se convirtió en un ícono de los forajidos. En 2010, el gobierno exaltó la imagen de Juan Pablo Bolaños, el único civil fallecido en las manifestaciones de respaldo al oficialismo, así como del policía del GIR, Froilán Jiménez, quien murió durante el operativo de "rescate" al presidente. En 2019, se intentó posicionar la figura del periodista Freddy Paredes, herido por una pedrada en la cabeza, como muestra del vandalismo de los 
Tabla No. 1

Incidencia de medios según cada revuelta

\begin{tabular}{|c|l|c|c|c|}
\hline \multicolumn{2}{|c|}{} & \multicolumn{3}{c|}{ Nivel de incidencia } \\
\hline \multirow{2}{*}{ Revueltas } & \multicolumn{1}{|c|}{ Medios } & Alta & Media & Baja \\
\hline \multirow{3}{*}{$\begin{array}{c}\text { Caída de Gutiérrez } \\
(2005)\end{array}$} & Plataformas digitales & & & $\mathrm{X}$ \\
\cline { 2 - 5 } & Medios tradicionales & $\mathrm{X}$ & & \\
\cline { 2 - 5 } & Censura gubernamental & & & $\mathrm{X}$ \\
\hline
\end{tabular}

\begin{tabular}{|c|l|l|l|l|}
\hline \multirow{2}{*}{$\begin{array}{c}305 \\
(2010)\end{array}$} & Plataformas digitales & & $X$ & \\
\cline { 2 - 5 } & Medios tradicionales & & & $X$ \\
\cline { 2 - 5 } & Censura gubernamental & $X$ & & \\
\hline
\end{tabular}

\begin{tabular}{|c|l|c|c|c|}
\hline \multirow{2}{*}{$\begin{array}{c}\text { Paro 0ctubre } \\
\text { (2010) }\end{array}$} & Plataformas digitales & $\mathrm{X}$ & & \\
\cline { 2 - 5 } & Medios tradicionales & $\mathrm{X}$ & & \\
\cline { 2 - 5 } & Censura gubernamental & & $\mathrm{X}$ & \\
\hline
\end{tabular}

Fuente: Elaboración propia. La tipología de medios y censura en "medios alternativos" y "medios tradicionales" corresponden, en su orden, a la lógica de "producción de lo común" y al papel de la "opinión pública" (Hardt \& Negri, 2004); mientras que la "censura gubernamental", tiene relación con la "verdad factual" (Arendt, 2018)

manifestantes; sin embargo, la opinión pública no actuó de la misma manera sobre los 11 fallecidos civiles durante el paro, y sobre quienes el gobierno enfatizó que murieron por accidentes y no por disparos como denunciaron las organizaciones de derechos humanos y los medios alternativos.

37 Hasta la actualidad (marzo 2020) no existe confirmación oficial del número exacto y la causa de muerte de los fallecidos durante el paro de octubre. La versión de que los policías fueron las "victimas" de la protesta y no los "victimarios" de la represión, incluso ha intentado apalancarse en una reinterpretación de los derechos humanos que se fundamenta en la pregunta si los policías también son sujetos de estos derechos universales.

38 El entonces alcalde capitalino, Paco Moncayo, y el Prefecto de Pichincha, Ramiro González, ambos de la ID para la época, promovieron la denominada "marcha de Quito", mientras que Jaime Nebot hizo lo propio en Guayaquil.

39 Entre las que se incluyeron radio La Calle, Voces, Wambra Radio, entre otras, que denunciaron represión y censura por parte del gobierno a través de la inhibición de la señal de celulares en los sitios de conflicto como la Casa de la Cultura Ecuatoriana, en Quito. 


\section{Bibliografía}

Althusser, Louis (2005) La filosofía como arma de la revolución. Incluye los aparatos ideológicos del Estado. Vigésima quinta edición. México: Siglo XXI.

Arendt, Hannah (2018) Verdad y mentira en la política. 2da. Reimpresión. Barcelona: Página Indómita.

Correa, Rafael (2011) Una lección de la experiencia, en 30S. La Contrarrevolución. Segunda edición. Quito: Ministerio de Coordinación de la Política y Gobiernos Autónomos Descentralizados.

Eco, Humberto (1984) Apocalípticos e integrados. 7 ma. Edición. Madrid: Lumen.

Gaussens, Pierre (2011) ¿Primavera árabe o reconfiguración imperial? Esperanzas y límites de la movilización social en el Medio Oriente. Quito: Revista del Centro Andino de Estudios Internacionales. No. 11.

Hardt, Michael y Antonio Negri (2004). Multitud. Guerra y democracia en la era del imperio. Buenos Aires: Debate.

Hurtado, Edison (2005) "Lo que pasó en Ciespal". Apuntes etnográficos sobre el poder, los medios y el sin-sentido de la violencia, en Revista Íconos No.23. Quito: Flacso-Ecuador.

Instituto Nacional de Estadísticas y Censos (2014). IV Encuesta de Condiciones de Vida.

Lobo, Sascha (2016) Cómo influyen las redes sociales en las elecciones. en Revista Nueva Sociedad No. 269 Mayo-Junio 2017. Buenos Aires: Nueva Sociedad.

Montalvo, Daniel et. all (2020) Cultura política de la democracia en Ecuador y las Américas. 2018/19. Tomándole el pulso a la democracia. Quito: Vanderbilt University.

Morozov, Evgeny (2011). El desengaño de internet. Los mitos de la libertad en la red. Barcelona: Destino.

Quintero, Rafael y Erika Sylva (2011). La alianza de la derecha y el corporativismo en el "Putch" del 30 de septiembre de 2010, en 30S. La Contrarrevolución. Segunda edición. Quito: Ministerio de Coordinación de la Política y Gobiernos Autónomos Descentralizados.

Tarrow, Sidney (2004). Los movimientos sociales, la acción colectiva y la política. Madrid: Alianza 